Original Research

\title{
A study of job insecurity and life satisfaction in COVID-19: the multilevel moderating effect of perceived control and work-life balance programs
}

\author{
Meng-Hsiu Lee ${ }^{1}$, Hung-Yu Tsai ${ }^{2} *$ \\ ${ }^{1}$ Department of Management Sciences, Tamkang University, 25137 Taipei, Taiwan \\ ${ }^{2}$ Nanfang College of Sun Yat-sen University, 510970 Guangzhou, Guangdong, China \\ *Correspondence: s997205@gmail.com (Hung-Yu Tsai) \\ Submitted: 5 July 2021 Accepted: 19 October 2021 Published: 19 January 2022
}

\begin{abstract}
Background: The effect of COVID-19 on the manufacturing industry in China has resulted in increased employee psychological pressure and job insecurity. This study uses a theoretical model to identify the links between job insecurity and life satisfaction, and further explores the multilevel moderating effect underlying these links. Methods: Based on the conservation of resources theory, a hierarchical linear model is utilized to test the relationships among cross-level variables. The data comprises 528 valid questionnaires from 43 manufacturing companies in China. Results: The research results show that both perceived control (individual level) and work-life balance programs (organizational level) positively moderate the relationship between job insecurity and life satisfaction. Conclusions: This study contributes toward identifying the effect of employees' psychological status and job insecurity on life satisfaction, and further confirms two different level moderators that alleviate the negative relationship between job insecurity and life satisfaction. Whether different genders have an effect on perception of life satisfaction is also considered, and the results show that men perceive significantly greater life satisfaction than women. Finally, based on the research findings, practical and theoretical implications are proposed.
\end{abstract}

Keywords: Job insecurity; Life satisfaction; Perceived control; Work-life balance program; Multilevel analysis

\section{Introduction}

The COVID-19 pandemic has caused widespread concern, fear and stress. The issue faced by each individual is how to manage themselves and cope during a rapidly unfolding stressful period [1]. The disruptive effects of the COVID-19 crisis, including social distancing measures, mental health issues and future employment, should be acknowledged, understood, and addressed by individuals, communities and governments to ensure that the impact of the pandemic on people's lives is seriously considered [2].

Worldwide, the ongoing impact of COVID-19 has significantly increased the level of uncertainty in workplaces [3]. In particular, in China's manufacturing industry, employees frequently experience concern regarding the future of their employment and job insecurity during periods of job suspension and resumption [4]. As a result of COVID19 , job insecurity is defined as perceived powerlessness to maintain desired continuity in a threatened job situation $[5,6]$. According to research, the consensus is that job insecurity and feelings of uncertainty about the future of one's employment are associated with a number of negative consequences [7-11].

Previous studies on job insecurity indicate that events such as the COVID-19 pandemic exert negative effects on the emotions and behaviors of employees, including their health, well-being, attitudes [12], performance [7,9,11,13], and the psychological contract [12], which can lead to de- creased job satisfaction and organizational commitment [7]. Employees encountering job insecurity may develop negative feelings toward the event, which then negatively affects their work-life behavior. Therefore, within human resource (HR) practices, there is an increased focus on job insecurity and employees' personal outcomes. Owing to the COVID19 pandemic, this is largely reflected across the world in a bid to mitigate negative workplace effects.

The conservation of resources (COR) theory states that individuals have limited time, energy, brainpower, and emotional resources [14]. When faced with job insecurity, an individual's limited resources can deplete rapidly [15]. Depletion of an individual's resources not only affects personal behavior, but also mental and physical health [16]. Therefore, this study first investigates the negative impact of job insecurity on life satisfaction.

Previous studies mostly examine the moderating effects of employees' personality traits $[17,18]$, organizational justice [19], psychological capital [20], perceived control [21], and organizational safety climate [22]. Few studies, however, explore perceived control and/or an organization's work-life balance programs (WLBP) to investigate the moderating effects of job insecurity on employees. Examining the latter can provide references for organizations or HR practices to assist employees in recovering from the negative effects of job insecurity. As such, this study explores the types of personal and contextual resources that 
organizations can use to effectively assist employees in alleviating the harmful effects of negative workplace stress (job insecurity) and, therefore, facilitate personal life satisfaction. How an employee's perceived control and an organization's WLBP moderate this relationship is also investigated.

To contribute to the literature on job insecurity and negative workplace reflection, this study investigates how workplace stressors, such as job insecurity, elicit responses in employees who eventually become motivated toward negative employee outcomes (life satisfaction). Whether perceived control and WLBP can mitigate job insecurity induced work-life conflict is also examined. When an individual has higher perceived control, they may effectively control their own mental state and behavioral output. Thus, when they are faced with changes to their external environment (e.g., COVID-19), they may still be able to prevent negative impacts on their own living conditions. Empirical research also states that when an individual has perceived control, it reduces their work-life conflicts [23].

Conversely, individuals with lower perceived control will have poor control over their own mental state and as such, their daily life is more likely to be affected by external environmental changes. Individuals who lack perceived control are more likely to negatively influence their behavior, motivation, and psychological and physical health [24]. However, when employees implement perceived control and employers execute WLBP to temporarily pause workrelated issues, both physiologically and psychologically, many employees are proactive in easing job insecurity. By creating perceived control via WLBP, employees are less likely to develop negative work outcomes, even when they are concerned about job insecurity, and thus can maintain life satisfaction. Furthermore, this research attempts to understand the psychological impact of the COVID-19 outbreak among employees and whether it is meaningful for organizational policies and personnel to maintain employee life satisfaction as a practical implication.

Finally, whether the relationship between the variables is impacted by gender differences is also investigated. Gender is used as one of the control variables to clarify the coefficient of gender in the conceptual framework. Furthermore, a t-test is performed to clarify whether gender differences may cause alternate perceptions on life satisfaction. To address the problem of insufficient research, this study proposes a theoretical framework to investigate the relationships among the variables.

\section{Theoretical development and hypotheses}

\subsection{Relationship between job insecurity and life satisfaction}

This research adopts the COR theory [25] as the principal theory to explain the relationships among variables. The COR theory states that people have the basic motivation to preserve, protect, and create valued resources. The speed of resource consumption can accelerate when a person is under long-term pressure [26]. Therefore, when an individual faces job insecurity, there is a loss of inner resources. If these inner resources are not replaced immediately, or the replacement supply is less than that which is lost, a secondary loss of inner resources can occur [27]. If the organization is unable to provide adequate resources or none at all, employees will not have enough inner resources to adjust their behaviors and attitudes [28], leading to negative employee outcomes and behaviors.

Throughout all countries and societies, COVID-19 has had a profound impact on psychological well-being and the workplace. This study focuses on job insecurity as it is one of the stressors faced by employees. Based on the COR theory, when individuals face job insecurity from the COVID19 pandemic, they must deal with continued work demands, while the speed of their personal resource loss rises significantly. Consequently, employees need to put in additional effort to deal with job insecurity $[7,9,13]$. The result of continuous personal resource loss is the complete depletion of all personal resources [29]. According to a metaanalysis, job insecurity has a positive relationship with job stress $[11,30]$.

This study assumes that job insecurity can be regarded as a source of personal stress for employees as they may perceive threats to their job as a whole [11] or that job insecurity may be a reflection of the forecast for the event (e.g., the COVID-19 pandemic) $[31,32]$. This uncertainty leads them to perceive the loss of personal resources without the ability to replenish them, causing both physical and psychological discomfort [33]. If this condition persists, employees may experience reduced life satisfaction.

In summary, when employees perceive job insecurity and fail to regain their positive state in time, other workplace stressors are more likely to have a negative effect, which may damage their life satisfaction status. Accordingly, this study proposes the following hypothesis:

Hypothesis 1: Job insecurity is negatively related to life satisfaction.

\subsection{Individual level moderating effect of perceived control}

Organizations are increasingly utilizing perceived control as it leads to reduced job stress among employees [34]. Based on Wallston, Smith and Dobbins (1987) [35], perceived control is an individual's perception of an external event, and their ability to control and process the event. Furthermore, psychologically, individuals can adjust their perception of the event and control the subsequent behavioral output. Individuals who believe that they can control various dimensions of their environment and their workload, and adapt to the pressure of learning can reduce this pressure. This is known as perceived control.

Perceived control is also a type of psychological control used to determine the internal state and behavior of individuals [35]. Ajzen [36] believes that individuals conduct 
self-evaluations to check whether they have sufficient control ability. Therefore, this study posits that perceived control is an individual's ability to control themself, as well as their plans and goals they can achieve by controlling themself. The findings of previous studies also indicate that perceived control is an important factor affecting behavioral intentions and can positively improve life satisfaction and job performance [37,38].

According to the COR model, as a result of the COVID-19 pandemic, employees facing daily work-related problems, that could lead to job insecurity may also experience a reduction in life satisfaction and quality [39]. Furthermore, continuous stress and tension will reduce life satisfaction, even if employees leave their workplace [40]. This study infers those employees with a high level of perceived control have better control over their external environment as well as their own affairs and goals. Therefore, compared to individuals with a relatively low level of perceived control, they are less vulnerable to the negative effects of environmental changes and job uncertainty. Accordingly, this study proposes the following hypothesis:

Hypothesis 2: Perceived control will moderate the relationship between job insecurity and life satisfaction. This relationship will be weaker when perceived control is higher.

\subsection{Organizational level moderating effect of WLBP}

Previous literature states that high levels of worklife balance are associated with increased job satisfaction among employees as they facilitate employee perceived control [41]. Once the organization provides the opportunity for WLBP, employees can enhance perceived selfmanagement and control and experience higher job satisfaction $[42,43]$. When implementing WLBP, certain factors need to be considered. For instance, WLBP needs to be adjusted to the specific needs of the employees as well as being part of the organizational culture to obtain the positive effect of employee job satisfaction, thereby promoting organizational success [44-47]. The use of WLBP within organizations helps employees separate their work and life responsibilities.

An organization creates WLBP to retain employees, eliminate work stress and take care of employees' minds and bodies [48]. According to the COR theory, if an organization protects its employees, it not only eases job stress and enhances objective resources, but also allows employees to feel cared for by the organization, thereby enhancing personal social resources [48]. When an organization creates home-friendly support policies, the negative effects of job insecurity can be eased $[49,50]$. Thus, if the organization provides WLBP, it can resupply the employee's personal and social resources. Under these conditions, employees may have more energy to deal with job insecurity that may be caused by the COVID-19 pandemic, resulting in increased life satisfaction.
In contrast, if employers do not implement WLBP to temporarily mitigate the effects of job insecurity, the cognitive and personal resources that were expended to confront the job insecurity will not be replenished and the resultant negative work effects will persist [51]. Moreover, employees may exacerbate stress and negative cognition, which can increase their work-related problems and reduce life satisfaction [49]. Accordingly, this study proposes the following hypothesis, and the conceptual framework for this study is displayed in Fig. 1.

Hypothesis 3: WLBP moderates the relationship between job insecurity and life satisfaction. This relationship will be weaker when WLBP is higher.

\section{Method}

\subsection{Sampling and procedures}

COVID-19 has already had an extensive impact on the Chinese economy. Some manufacturing companies are still unable to resume work under the influence of prevention and control policies. As the foundation of China's economy, the manufacturing industry currently faces multiple overlapping risks, which may cause serious damage to the Chinese economy and directly affect economic growth. Chinese manufacturing employees were used for sampling to investigate the uncertainty of job insecurity and the subsequent psychological impact.

Manufacturing companies in China (including Taiwan) with at least a medium-sized business scale (more than 250 employees) in both the private and public sectors were sampled. Owing to multilevel frameworks, data were collected from employees and their HR managers within the same companies, during 2020. The valid sample consists of 528 employees from 43 companies. From this sample, $64.4 \%$ of the respondents are men, $35.7 \%$ are women and most are aged between 21-30 years old. In terms of marital status and education level, the majority are single and undergraduates or college graduates.

Chinese manufacturing industry companies were contacted to confirm whether they had been affected by COVID-19. After the companies had resumed production, employees completed different sections of the questionnaires at different sampling times for cross-level (individual and organizational level) samples. Job insecurity, perceived control and WLBP were measured at Time 1. After two weeks, at Time 2, life satisfaction and demographic data were collected. The time lag method, using two different sampling time periods, was used to reduce the potential for common method variance.

\subsection{Measurements}

\subsubsection{Job insecurity (individual level)}

We used Feather and Rauter's [50] 3-item scale to measure job insecurity. A sample item is "I am worried about having to leave my job before I would like to". Participants answered each item using a rating scale ranging 


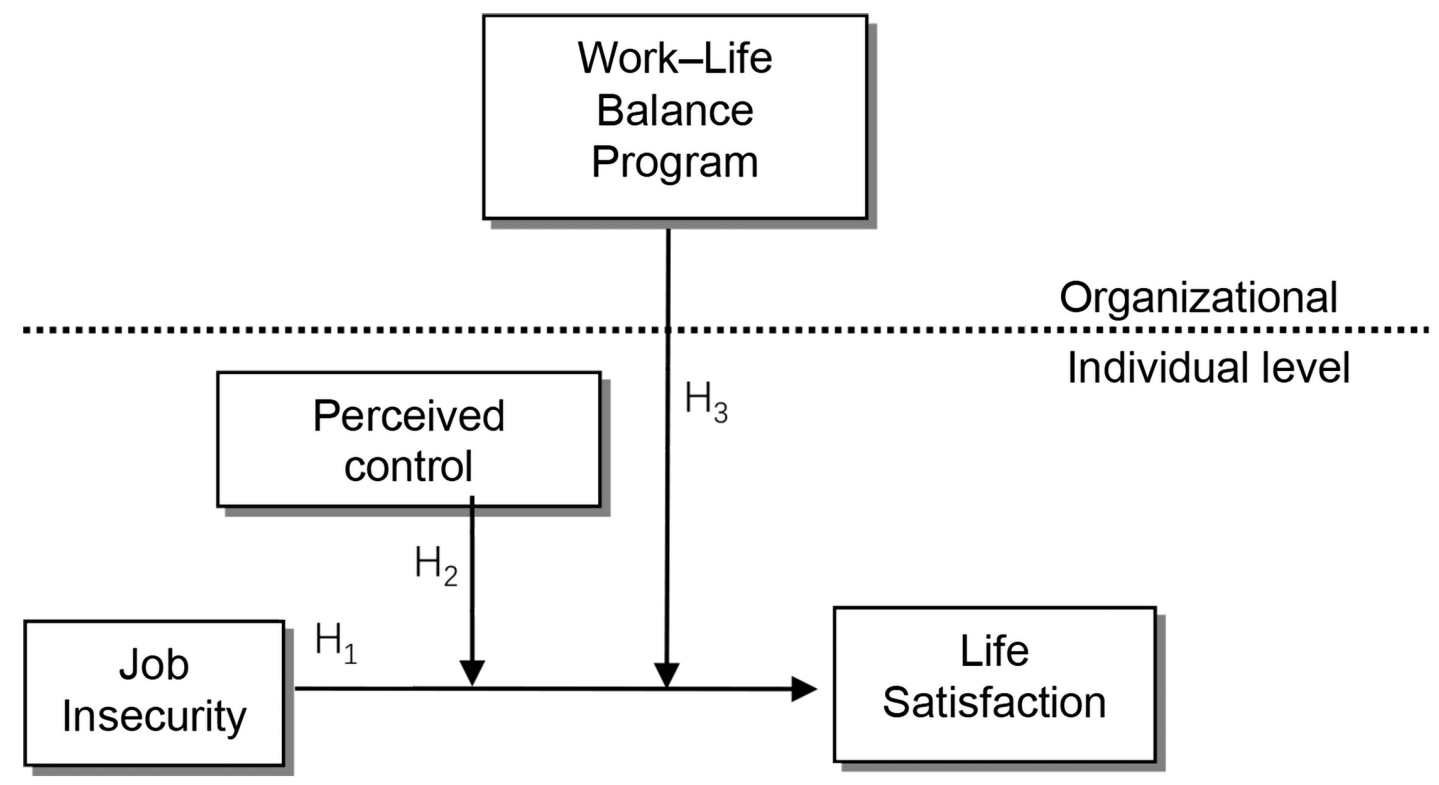

Fig. 1. The conceptual framework for this study.

from 1 (strongly disagree) to 5 (strongly agree). Cronbach's alpha was 0.86 . Higher scores indicated greater perceived job insecurity.

\subsubsection{Perceived control (individual level)}

The construct was measured by four items to test the extent of employees' perceived control of the timing and scheduling of work. The items were from a revised scale used by Kushnir and Melamed [51], and a sample item is "Employees can decide their schedules between work time and vacation time by themselves". Responses were recorded on a 5-point Likert scale ranging from 1 (strongly disagree) to 5 (strongly agree). Cronbach's alpha for the scale was 0.91 .

\subsubsection{Life satisfaction (individual level)}

Participants completed the satisfaction with life scale [52], which is a five-item measurement of life satisfaction. A five-point response scale ranging from "strongly disagree" to "strongly agree" was used. A sample item is "In most ways my life is close to my ideal". Cronbach's alpha for the scale was 0.87 .

\subsubsection{Work-life balance program (organizational level)}

To accurately identify whether the company provided a real work-life balance program for their employees, the questionnaire we selected was based on the revised Tiwari and Tyagi's [41] WLBP, with a five-point response scale ranging from "strongly disagree" to "strongly agree". The sample item was "Are you satisfied with flexible working hours, providing at your organization"? The mean score represented the degree to which the companies contribute their effort to work-life balance, and the mean was used to measure the moderating variables. Cronbach's alpha for the scale was 0.83 .

\subsubsection{Control variable}

Gender, age, education level, and tenure were control variables that were measured to control for individual levels because of their potential effects on work attitudes [53]. Firm size may affect the display strength of WLBP. The larger the firm size and revenue, the greater the capital, and possibly the more resources it can invest in adopting the strategy $[54,55]$. Thus, we controlled for firm size (number of employees) to ensure that the different control variables would not influence the research results. Thus, to avoid and control the irrelevant effects and clarify the relationship between perceived control, life satisfaction, and WLBP, we considered these five control variables.

\section{Data analysis}

We conducted a confirmatory factor analysis to assess the discriminant validity of the four constructs: job insecurity, life satisfaction, perceived control, and work-life balance. We chose five criteria to measure model fit $\left(\chi^{2}, \chi^{2} /\right.$ d.f., GFI, AGFI, and RMSEA, respectively). Drawing on the method used by Farh et al. [56], we tested four alternative models and compared them with the baseline fourfactor model (Table 1). The results indicated that the fourfactor model had a more adequate overall fit than the other models. The results also revealed that the four variables were distinct constructs.

Table 2 shows the scale internal composite reliability and variance extracted for the measures, which were above the cut off values of 0.7 and 0.5 [57]. Table 3 presents each variable's mean, standard deviations, and correlation matrix for the measurement variables. 
Table 1. Confirmatory factor analysis: discriminate validity.

\begin{tabular}{lccccc}
\hline Model & $\chi^{2}($ d.f. $)$ & $\chi^{2} /$ d.f. & GFI & AGFI & RMSEA \\
\hline Null model & $7815.6(1187)$ & 6.584 & 0.768 & 0.728 & 0.069 \\
One-factor model & $5563.4(1163)$ & 4.784 & 0.827 & 0.792 & 0.057 \\
Two-factor model & $5152.1(1152)$ & 4.472 & 0.832 & 0.816 & 0.055 \\
Three-factor model & $4188.3(1152)$ & 3.636 & 0.869 & 0.843 & 0.047 \\
Four-factor model (baseline model) & $2751.6(1152)$ & 2.389 & 0.912 & 0.901 & 0.034 \\
\hline
\end{tabular}

Note. GFI, goodness-of-fit index; AGFI, adjusted goodness-of-fit index; RMSEA, root mean square error of approximation.

Table 2. Measurement properties.

\begin{tabular}{lcccc}
\hline & Composite reliability & Variance extracted & Number of items & Cronbach's $\alpha$ \\
\hline Job insecurity & 0.94 & 0.72 & 3 & 0.87 \\
Perceived control & 0.90 & 0.72 & 4 & 0.82 \\
WLBP & 0.92 & 0.78 & 6 & 0.86 \\
Life satisfaction & 0.88 & 0.76 & 5 & 0.83 \\
\hline
\end{tabular}

Table 3. Descriptive statistics and correlations.

\begin{tabular}{lccccc}
\hline \multicolumn{5}{c}{ Variables } \\
\hline & Mean & SD & 1 & 2 & 3 \\
1. Job insecurity & 3.57 & 0.70 & & & \\
2. Perceived control & 3.55 & 0.77 & $-0.223^{*}$ & & \\
3. Life satisfaction & 3.73 & 0.59 & $-0.328^{* *}$ & $0.287^{*}$ & \\
4. WLBP & 3.88 & 0.63 & -0.042 & 0.102 & $0.251^{*}$ \\
\hline
\end{tabular}

Notes: ${ }^{*} p<0.05,{ }^{* *} p<0.01$, WLBP, work-life balance programs.

We examined aggregation statistics, including $\operatorname{ICC}(1)$ and ICC(2) [58], and the within-group agreement of multiple items $R w g$ [59]. The ICC(1) scores of perceived control and WLBP were 0.26 and 0.28 , respectively. The ICC(2) values of these variables were 0.69 and 0.68 , respectively. The mean $R w g$ values were 0.85 and 0.83 , respectively.

\section{Results}

As reported in Model 2 of Table 4, job insecurity was significantly negatively related to life satisfaction $(\gamma=-$ $0.33, p<0.01)$. Thus, support was found for Hypothesis 1. Next, we evaluated Hypothesis 2 (Table 4). In Model 2 , perceived control was significantly positively related to life satisfaction $(\gamma=0.21, p<0.05)$. In Model 3, job insecurity $\times$ perceived control interaction was positively and significantly related to life satisfaction $(\gamma=0.19, p<0.05)$. Therefore, Hypothesis 2 was supported. Furthermore, to clarify the moderating effect of perceived control, we plotted the job insecurity-life satisfaction relationships under high (1 SD above the mean) and low (1 SD below the mean) levels of perceived control (see Fig. 2). As shown in Fig. 2, the negative effect of job insecurity on life satisfaction was lower when the level of perceived control was high, and vice versa, thus illustrating the moderating effect.

Model 3 of Table 4 presents the results of testing Hy-
Table 4. Hierarchical linear modeling results for multilevel-moderating effect.

\begin{tabular}{lccc}
\hline & \multicolumn{3}{c}{ Life satisfaction } \\
\hline & Model 1 & Model 2 & Model 3 \\
Level 1: Individual & & & \\
$\quad$ Slopes $\gamma 00$ & $2.93^{* *}$ & $2.87^{* *}$ & $2.51^{*}$ \\
$\quad$ Gender & 0.03 & 0.000 & 0.000 \\
$\quad$ Age & -0.13 & -0.12 & -0.082 \\
$\quad$ Education level & 0.08 & 0.07 & 0.05 \\
$\quad$ Tenure & 0.01 & 0.00 & 0.02 \\
Job insecurity (JI) & & $-0.33^{* *}$ & -0.18 \\
Perceived control (PC) & & $0.21^{*}$ & 0.04 \\
JI*PC & & & $0.19^{*}$ \\
Level 2: Organizational & & & \\
$\quad$ Firm size & 0.13 & 0.11 & 0.02 \\
$\quad$ WLBP & & $0.42^{* *}$ & $0.24 *$ \\
$\quad$ JI*WLBP & & & $0.37^{* *}$ \\
Covariance-components model & 695.4 & 1087.3 & 1095.9 \\
$R^{2}$ & 0.12 & 0.36 & 0.51 \\
\hline
\end{tabular}

Notes: ${ }^{*} p<0.05,{ }^{* *} p<0.01$, for employees, $\mathrm{N}=528$; for units, $\mathrm{N}=43$. 


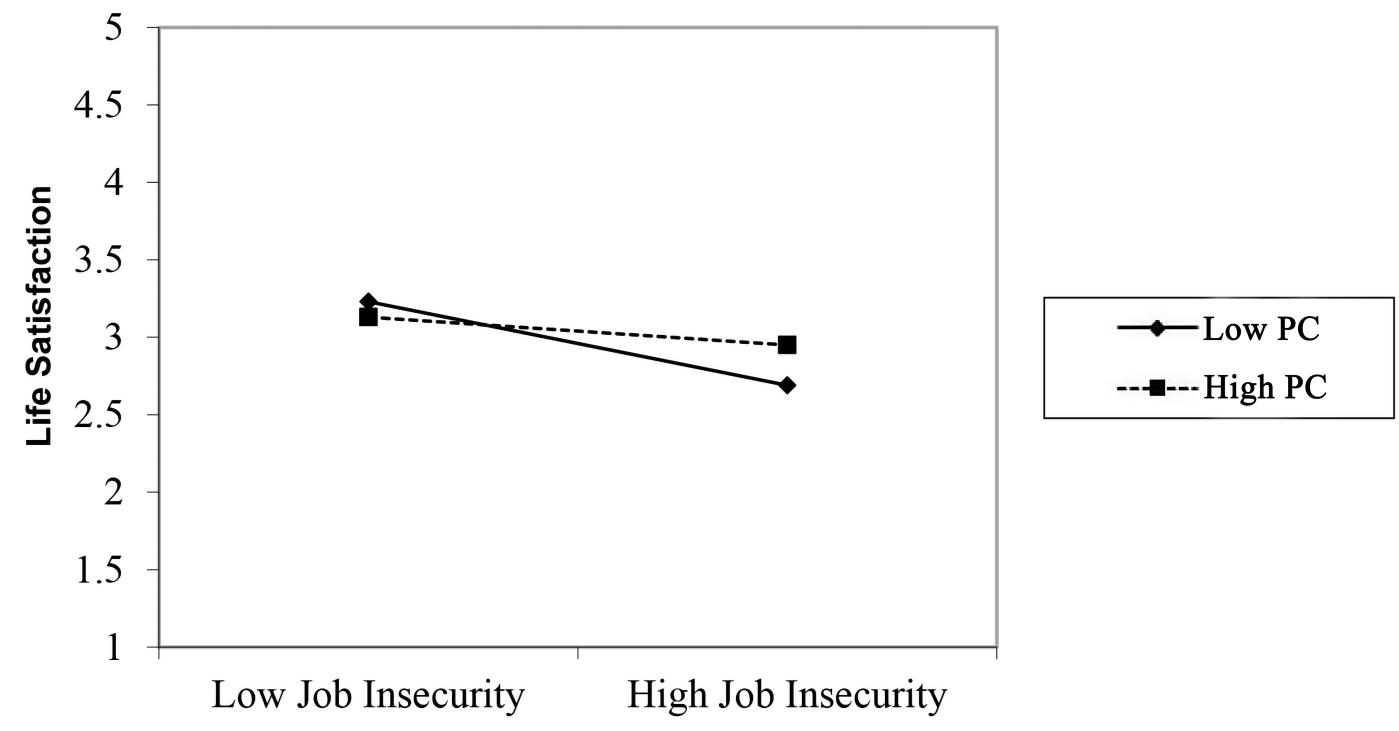

Fig. 2. The moderating effect of Perceived Control.

pothesis 3, according to which WLBP positively moderates the job insecurity-life satisfaction relationship $(\gamma=0.37$, $p<0.01)$. The meso-moderated model explained $51 \%$ of the variance in the outcome variable $\left(R^{2}=0.51\right)$. Therefore, the negative effect of job insecurity on life satisfaction was lower when the level of WLBP was high, and vice versa, supporting Hypothesis 3. To clarify the moderating effect of WLBP, we also plotted the job insecurity-life satisfaction relationships under high and low levels of WLBP (see Fig. 3). As shown in Fig. 3, the negative effect of job insecurity on life satisfaction was lower when the level of WLBP was high, and vice versa.

Finally, we performed a $t$-test to measure whether different genders have different views on life satisfaction. The mean life satisfaction was 3.78 for mens, and 3.6 for women. The results of the $t$-test can reach statistical significance $(\mathrm{t}=2.145, p<0.05)$. We further conducted Cohen's $\mathrm{d}$ tests to examine the significance of gender differences. Compared with women, mens are at higher life satisfaction ( $p<0.001$, Cohen's $\mathrm{d}=0.21)$. This means that men's perception of life satisfaction is significantly higher than that of women.

\section{Discussion}

\subsection{Theoretical implications}

The results of this study indicate that job insecurity has a negative impact on life satisfaction. According to the COR theory, employees with higher job insecurity have poorer mental and physical health, and display more negative work attitudes, which will eventually negatively affect life satisfaction [60]. The target sampling for this study was Chinese manufacturing employees experiencing job insecurity caused by the COVID-19 pandemic, as job insecurity as a workplace stressor also affects employees' life satisfac- tion. Based on the COR theory, when facing job uncertainty as a result of the COVID-19 pandemic, employees must exert more effort to deal with their job requirements as well as cope with job insecurity. The continuation of this situation will result in reduced life satisfaction, as confirmed in the results.

Furthermore, this study confirms that perceived control has a significant positive individual level moderating effect, which concurs with the argument of Rocereto et al. [61] that perceived control can reduce employees' work stress. Employees can temporarily forget work-related matters and stresses through perceived control and effectively recycle personal negative emotional resources. Therefore, when employees apply perceived control and are provided with flexibility during working hours, they are able to support their families without sacrificing their work, while simultaneously improving employee satisfaction [62].

This study also agrees with Krausz et al. [63], who found a significant relationship between perceived control and life satisfaction. Through perceived control to change cognition, employees are unlikely to increase negative work effects, even when experiencing job insecurity and maintaining life satisfaction. In addition, this study confirms the significant positive organizational level moderating effect of WLBP. It also supports Vohs and Heatherton's [28] argument that if the organization fails to provide adequate resources, employees will not have enough personal resources to adjust their behaviors and attitudes, which can lead to negative attitudes and behaviors.

Furthermore, this study supports the belief that WLBP can strengthen the positive relationship between perceived control and job satisfaction. Those organizations providing WLBP illustrate they empathize with the difficulties of balancing work and personal life. Thus, employees appre- 


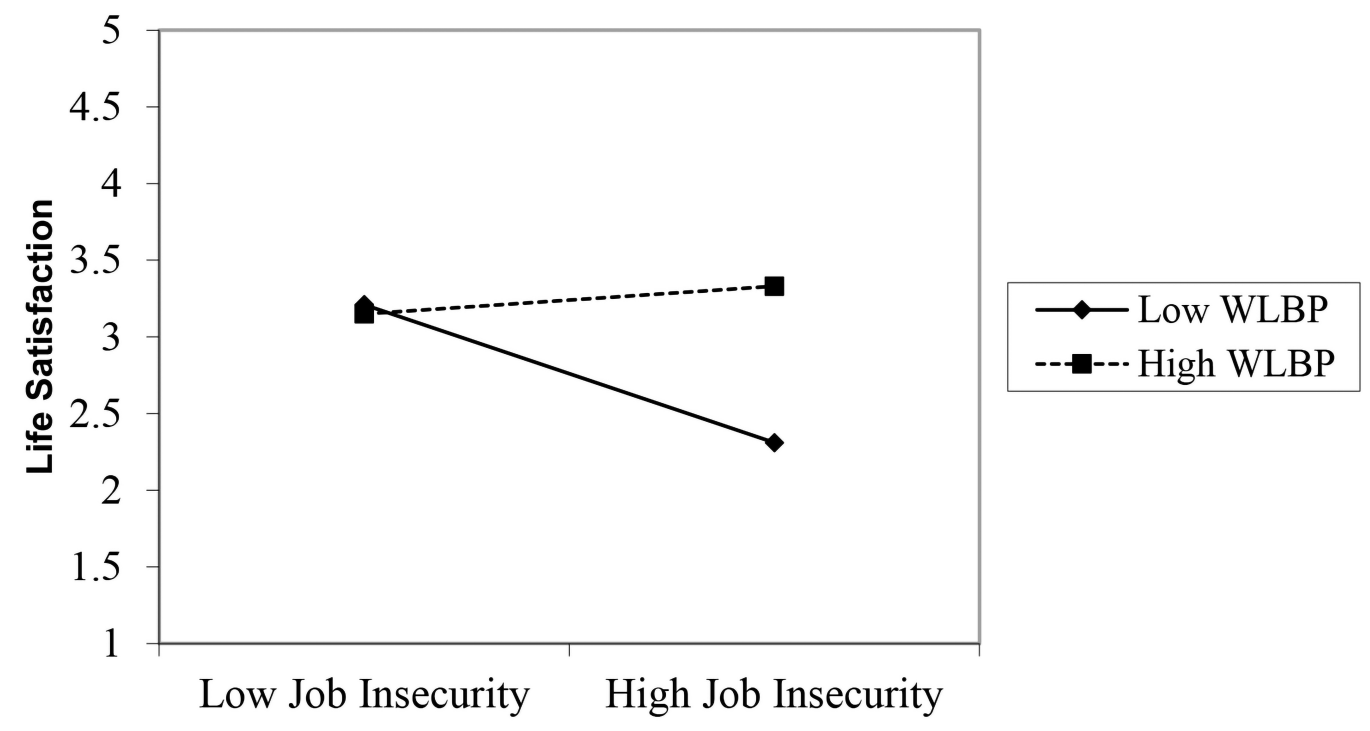

Fig. 3. The multilevel moderating effect of WLBP.

ciate the provided WLBP and are willing to accept them. This helps employees acknowledge that the organization not only prioritizes profit, but also cares about its employees and, therefore, increases their job satisfaction.

\subsection{Practical implications}

To reduce the negative psychological state of employees facing the impacts of COVID-19, HR or other relevant departments should execute policies that combine the following three aspects. First, it is necessary to understand the context of job insecurity and arrange professional counselors for consultation and advice. In particular, employees may worry that they may lose their jobs in the near future or be forced to leave. This psychological state directly negatively affects life satisfaction.

In addition, relevant courses or resources should be provided to allow employees to have the power and ability of perceived control. In particular, employees could arrange their work hours and vacation time, as when employees are free to decide their work pace, they are also free to decide how to carry out their work. Providing them with the ability to arrange and control work will help reduce the negative pressure caused by job insecurity.

Second, high-level management should also design and implement WLBP and other related HR policies to effectively alleviate the negative psychological state of employees during the COVID-19 pandemic. Specifically, WLBP should include flexible working hours, so that employees can easily arrange work hours and holidays, benefits for caring for family, employee assistance programs and compensation packages. When an organization can formulate and implement a mature WLBP, it may dilute the negative relationship between job insecurity and life satisfaction caused by the COVID-19 pandemic.
Third, when HR practitioners implement WLBP, life satisfaction can be improved. When employees are satisfied with their lives, they think they have what they want and feel no need for change. Their lives are close to their ideal states with excellent living conditions.

Additionally, male employees have significantly higher life satisfaction than female employees. It is suggested that supervisors provide employees with WLBP tailored toward female employees. These could include a care policy to help eliminate work stress and take care of employees' physical and mental well-being. This can reduce women's work-family conflicts and improve their life satisfaction. Furthermore, in considering the needs and personal situations of male employees, supervisors should provide them with a reward policy, for example, incentives and material compensation.

In conclusion, establishing communication policies and providing care and reward policies to employees will make them feel appreciated by their companies.

\subsection{Limitations and implications for future research}

This study has some limitations that should be addressed. The variable data regarding self-rated job insecurity, life satisfaction, perceived control and WLBP were collected from the same sources. Therefore, common method variance (CMV) problems may have influenced the results [64]. First, the data regarding the dependent variables were collected at different times. To avoid CMV bias, questionnaires were administered at different times, with an interval of two weeks between Time 1 and 2. Second, if this study encountered a significant CMV problem, the one-factor model should have demonstrated a superior fit index to that of the proposed model. However, the onefactor model exhibited a lower fit than the proposed 4-factor 
model. These results suggest that CMV problems do not significantly influence the research findings.

The second limitation is the design of this study. Because of the cross-sectional characteristics of the study, job insecurity has a relatively low base rate. Despite these limitations, significant results were obtained and the findings support the hypotheses. It is suggested that future studies use the experience sampling method, while extensively collecting samples to improve the generalizability of the results.

Third, longitudinal studies exploring how job insecurity and life satisfaction are related to employees' changing self-resource states as well as WLBP should be conducted in future research. It will be beneficial for future researchers to simultaneously include resource-based mechanisms and examine how these mediators differentially explain the effects of job insecurity. Furthermore, although this study takes the COR theory as its primary theory, it lacks verification of the mechanism of personal resource consumption and recovery. Therefore, future research should consider including personal resource consumption, recovery experience and the need for recovery as the intermediary processes of personal resource status, in order to explore the personal internal resources status. The moderator variable can be included in recovery-related self-efficacy. According to Sonnentag and Kruel [65], recovery-related selfefficacy plays an important role in the recovery effect of recovery activities for individuals.

Finally, perceived control may correlate with actual control, particularly given that employees could have adequate experience with their workplace system (e.g., WLBP) to be able to form accurate perceptions of control. Therefore, there may be an indirect or other relationship between perceived control and WLBP, and it is recommended that future research considers this.

\section{Conclusions}

Under the influence of COVID-19, Chinese manufacturing companies must pay attention to the moderating effect of both perceived control and WLBP to reduce the negative impact of job insecurity on life satisfaction. Individuals' perceived control, combined with the organization's implementation of WLBP, has a significant effect in alleviating the negative impact of job insecurity. In addition, the moderating effect of WLBP is greater than that of perceived control. Organizations should prioritize the implementation of WLBP to reduce the negative effects of job insecurity, especially during the COVID-19 pandemic.

Furthermore, women's life satisfaction is significantly lower than that of men. According to the COR theory [66], men accumulate family responsibilities over time, so male employees will experience work-life conflicts. However, women are more likely to be responsible for childcare and other home duties [66], which will lead to more work-life conflicts and, ultimately, reduced life satisfaction during the pandemic. Therefore, in the face of workplace uncertainty and pressure during the pandemic, employees who have better tolerance and flexibility to adapt to work-life conflicts will have higher life satisfaction.

\section{Abbreviations}

$\mathrm{CMV}$, common method variance; COR, conservation of resources; HR, human resources; WLBP, work-life balance program.

\section{Author contributions}

MHL designed the research study, performed the research; HYT performed the sampling and analyzed the data; All authors read and approved the final manuscript.

\section{Ethics approval and consent to participate}

The Governance Framework for Human Research Ethics of National Cheng Kung University (NCKU-HREC) approved the study. All subjects gave their informed consent for inclusion before they participated in the study.

\section{Acknowledgment}

The authors would like to thank Yang Jing (Fujian Jiangxia University) for the elaborate discussion about the research method.

\section{Funding}

This research received no external funding.

\section{Conflict of interest}

The authors declare no conflict of interest.

\section{References}

[1] Guicciardi M, Pazzona R. The rebooting in sports and physical activities after COVID-19 Italian lockdown. Frontiers in Psychology. 2020; 11: 607233 .

[2] Martinez-Martin N, Dasgupta I, Carter A, Chandler JA, Kellmeyer P, Kreitmair K, et al. Ethics of digital mental health during COVID-19: Crisis and opportunities. JMIR Mental Health. 2020; 7: e23776.

[3] Charoensukmongkol P, Phungsoonthorn T. The effectiveness of supervisor support in lessening perceived uncertainties and emotional exhaustion of university employees during the COVID-19 crisis: the constraining role of organizational intransigence. The Journal of General Psychology. 2020; 148: 431-450.

[4] Teng YM, Wu KS, Lin KL, Xu D. Mental health impact of COVID-19 on quarantine hotel employees in China. Risk Management and Healthcare Policy. 2020; 13: 2743-2751.

[5] Blomqvist S, Xu T, Persitera P, Låstad L, Magnusson Hanson LL. Associations between cognitive and affective job insecurity and incident purchase of psychotropic drugs: a prospective cohort study of Swedish employees. Journal of Affective Disorders. 2020; 266: 215-222.

[6] Greenhalgh L, Rosenblatt Z. Job Insecurity: toward Conceptual Clarity. Academy of Management Review. 1984; 9: 438-448.

[7] Cheng GH-, Chan DK-. Who Suffers more from Job Insecurity? A Meta-Analytic Review. Applied Psychology. 2008; 57: 272 303 . 
[8] De witte H, Pienaar J, De cuyper N. Review of 30 Years of Longitudinal Studies on the Association between Job Insecurity and Health and well-being: is there Causal Evidence? Australian Psychologist. 2016; 51: 18-31.

[9] Gilboa S, Shirom A, Fried Y, Cooper C. A meta-analysis of work demand stressors and job performance: examining main and moderating effects. Personnel Psychology. 2008; 61: 227271.

[10] Richter A, Vander Elst T, De Witte H. Job insecurity and subsequent actual turnover: Rumination as a valid explanation? Frontiers in Psychology. 2020; 11: 712-723.

[11] Sverke M, Hellgren J, Näswall K. No security: A meta-analysis and review of job insecurity and its consequences. Journal of Occupational Health Psychology. 2002; 7: 242-264.

[12] Vander Elst T, De Cuyper N, Baillien E, Niesen W, De Witte H. Perceived Control and Psychological Contract Breach as Explanations of the Relationships between Job Insecurity, Job Strain and Coping Reactions: towards a Theoretical Integration. Stress and Health. 2016; 32: 100-116.

[13] Piccoli B, Callea A, Urbini F, Chirumbolo A, Ingusci E, De Witte H. Job insecurity and performance: the mediating role of organizational identification. Personnel Review. 2017; 46: 1508-1522.

[14] Hobfoll SE. Social and Psychological Resources and Adaptation. Review of General Psychology. 2002; 6: 307-324.

[15] Lapierre LM, Allen TD. Work-supportive family, familysupportive supervision, use of organizational benefits, and problem-focused coping: implications for work-family conflict and employee well-being. Journal of Occupational Health Psychology. 2006; 11: 169-181.

[16] Karatepe OM, Baddar L. An empirical study of the selected consequences of frontline employees' work-family conflict and family-work conflict. Tourism Management. 2006; 27: 10171028.

[17] Kausto J, Elo A, Lipponen J, Elovainio M. Moderating effects of job insecurity in the relationships between procedural justice and employee well-being: Gender differences. European Journal of Work and Organizational Psychology. 2005; 14: 431-452.

[18] Näswall K, Sverke M, Hellgren J. The moderating role of personality characteristics on the relationship between job insecurity and strain. Work \& Stress. 2005; 19: 37-49.

[19] Wang H, Lu C, Siu O. Job insecurity and job performance: the moderating role of organizational justice and the mediating role of work engagement. The Journal of Applied Psychology. 2015; 100: 1249-1258.

[20] Lam CF, Liang J, Ashford SJ, Lee C. Job insecurity and organizational citizenship behavior: exploring curvilinear and moderated relationships. The Journal of Applied Psychology. 2015; 100: 499-510.

[21] Elst TV, De Cuyper N, De Witte H. The role of perceived control in the relationship between job insecurity and psychosocial outcomes: moderator or mediator? Stress and Health. 2011; 27: e215-e227.

[22] Probst TM. Safety and insecurity: exploring the moderating effect of organizational safety climate. Journal of Occupational Health Psychology. 2004; 9: 3-10.

[23] Wynn AT, Rao AH. Failures of Flexibility: how Perceived Control Motivates the Individualization of Work-Life Conflict. ILR Review. 2020; 73: 61-90.

[24] Pallant JF. Development and validation of a scale to measure perceived control of internal states. Journal of Personality Assessment. 2000; 75: 308-337.

[25] Hobfoll SE. Conservation of resources. a new attempt at conceptualizing stress. The American Psychologist. 1989; 44: 513524.

[26] Hobfoll SE, Shirom A. Conservation of resources theory: Ap- plications to stress and management in the workplace. In Golembiewski RT (ed.) Handbook of organizational behavior (pp. 5781). Dekker Press: New York, NY. 2001.

[27] Wang M, Liao H, Zhan Y, Shi J. Daily Customer Mistreatment and Employee Sabotage against Customers:Examining Emotion and Resource Perspectives. Academy of Management Journal. 2011; 54: 312-334.

[28] Vohs KD, Heatherton TF. Self-regulatory failure: a resourcedepletion approach. Psychological Science. 2000; 11: 249-254.

[29] Sonnentag S, Zijlstra FRH. Job characteristics and off-job activities as predictors of need for recovery, well-being, and fatigue. The Journal of Applied Psychology. 2006; 91: 330-350.

[30] Jiang L, Lavaysse LM. Cognitive and Affective Job Insecurity: a Meta-Analysis and a Primary Study. Journal of Management. 2018; 44: 2307-2342.

[31] Folkman S, Lazarus RS. If it changes it must be a process: Study of emotion and coping during three stages of a college examination. Journal of Personality and Social Psychology. 1985; 48: $150-170$.

[32] Boswell WR, Olson-Buchanan JB, Harris TB. I cannot Afford to have a Life: Employee Adaptation to Feelings of Job Insecurity. Personnel Psychology. 2014; 67: 887-915.

[33] Molino M, Cortese CG, Bakker AB, Ghislieri C. Do recovery experiences moderate the relationship between workload and work-family conflict? Career Development International. 2015; 20: $686-702$

[34] Xavier IM, Jepsen DM. The Impact of Specific Job Stressors on Psychological Contract Breach and Violation. Human Factors and Ergonomics in Manufacturing \& Service Industries. 2015; 25: 534-547.

[35] Wallston KA, Wallston BS, Smith S, Dobbins CJ. Perceived control and health. Current Psychology. 1987; 6: 5-25.

[36] Ajzen I. Perceived Behavioral Control, Self-Efficacy, Locus of Control, and the Theory of Planned Behavior1. Journal of Applied Social Psychology. 2002; 32: 665-683.

[37] Philippaers K, De Cuyper N, Forrier A. Employability and performance: The role of perceived control and affective organizational commitment. Personnel Review. 2019; 48: 1299-1317.

[38] Kiral Ucar G, Hasta D, Kaynak Malatyali M. The mediating role of perceived control and hopelessness in the relation between personal belief in a just world and life satisfaction. Personality and Individual Differences. 2019; 143: 68-73.

[39] Dong X, Zhao C, Yin H, Chen G. Work-family conflict affects job insecurity: the mediating role of core self-evaluation. Social Behavior and Personality: an International Journal. 2020; 48 $1-10$.

[40] Debus ME, Unger D, König CJ. Job insecurity and performance over time: the critical role of job insecurity duration. Career Development International. 2020; 25: 325-336.

[41] Tiwari DN, Tyagi SC. Impact of globalization on work-life balance in IFFCO, Aonla, Bareilly. International Journal of Research in Commerce \& Management. 2014; 5: 55-58.

[42] Sang KJC, Ison SG, Dainty ARJ. The job satisfaction of UK architects and relationships with work-life balance and turnover intentions. Engineering, Construction and Architectural Management. 2009; 16: 288-300.

[43] Smit BW. Successfully leaving work at work: the selfregulatory underpinnings of psychological detachment. Journal of Occupational and Organizational Psychology. 2016; 89: 493 514.

[44] Sánchez-Vidal ME, Cegarra-Leiva D, Cegarra-Navarro JG. Gaps between managers' and employees' perceptions of worklife balance. The International Journal of Human Resource Management. 2012; 23: 645-661.

[45] Chuang C, Liao H. Strategic human resource management in service context: taking care of business by taking care of employees 
and customers. Personnel Psychology. 2010; 63: 153-196.

[46] Nauman S, Zheng C, Naseer S. Job insecurity and work-family conflict. International Journal of Conflict Management. 2020; 31: 729-751.

[47] Richter A, Näswall K, Lindfors P, Sverke M. Job insecurity and work-family conflict in teachers in Sweden: Examining their relations with longitudinal cross-lagged modeling. PsyCh Journal. 2015; 4: 98-111.

[48] Eldridge D, Nisar TM. Employee and Organizational Impacts of Flexitime Work Arrangements. Articles. 2011; 66: 213-234.

[49] Lambert EG, Pasupuleti S, Cluse-Tolar T, Jennings M, Baker D. The Impact of Work-Family Conflict on Social Work and Human Service Worker Job Satisfaction and Organizational Commitment: An exploratory study. Administration in Social Work. 2006; 30: 55-74.

[50] Feather NT, Rauter KA. Organizational citizenship behaviours in relation to job status, job insecurity, organizational commitment and identification, job satisfaction and work values. Journal of Occupational and Organizational Psychology. 2004; 77: 81-94.

[51] Kushnir T, Melamed S. Work-load, perceived control and psychological distress in Type A/B industrial workers. Journal of Organizational Behavior. 1991; 12: 155-168.

[52] Diener E, Emmons RA, Larsen RJ, Griffin S. The Satisfaction with Life Scale. Journal of Personality Assessment. 1985; 49: 71-75.

[53] Jehn KA, Northcraft GB, Neale MA. Why Differences Make a Difference: a Field Study of Diversity, Conflict and Performance in Workgroups. Administrative Science Quarterly. 1999; 44: 741-763.

[54] Cappelli P, Hamori M. Are Franchises bad employer? Industrial and Labor Relations Review. 2008; 61: 147-162.

[55] Eldridge D, Nisar TM. The significance of employee skill in flexible work organizations. The International Journal of Human Resource Management. 2006; 17: 918-937.

[56] Farh JL, Hackett RD, Liang J. Individual level cultural values as moderators of perceived organizational support-employee outcomes relationships in China: Comparing the effects of power distance and traditionality. Academy of Management Journal. 2007; 50: 715-729.

[57] Hair JF, Black WC, Babin BJ, Anderson RE. Multivariate data analysis. 8th Edition. Andover UK: Cengage Learning EMEA. 2018.

[58] Kozlowski SWJ, Klein KJ. A multilevel approach to theory and research in organizations: Contextual, temporal, and emergent processes. In Klein KJ, Kozlowski SWJ (eds.) Multilevel theory, research, and methods in organizations: Foundations, extensions, and new directions (pp. 3-90). Jossey-Bass: San Francisco, CA. 2000.

[59] James LR, Demaree RG, Wolf G. Estimating within-group interrater reliability with and without response bias. Journal of Applied Psychology. 1984; 69: 85-98.

[60] Chirumbolo A, Callea A, Urbini F. The effect of job insecurity and life uncertainty on everyday consumptions and broader life projects during COVID-19 pandemic. International Journal of Environmental Research and Public Health. 2021; 18: 5363.

[61] Rocereto JF, Gupta SF, Mosca JB. The role of flextime appeal on family and work outcomes among active and non-active flextime users: A between groups and within groups' analysis. Journal of Business Economics. 2011; 9: 57-66.

[62] Halpern DF. How time flexible work policies can reduce stress, improve health, and save time. Stress Health. 2005; 21: 157168.

[63] Krausz M, Sagie A, Bidermann Y. Actual and preferred work schedule and scheduling control as determinants of job-related attitudes. Journal of Vocational Behavior. 2000; 56: 1-11.

[64] Podsakoff PM, Organ DW. Self-Reports in Organizational Research: Problems and Prospects. Journal of Management. 1986; 12: $531-544$.

[65] Sonnentag S, Kruel U. Psychological detachment from work during off-job time: the role of job stressors, job involvement, and recovery-related self-efficacy. European Journal of Work and Organizational Psychology. 2006; 15: 197-217.

[66] Trzebiatowski T, Triana MDC. Family Responsibility Discrimination, Power Distance, and Emotional Exhaustion: when and why are there Gender Differences in Work-Life Conflict? Journal of Business Ethics. 2020; 162: 15-29. 